\title{
Well-differentiated intrahepatic cholangiocarcinoma in the setting of biliary papillomatosis: A case report and review of the literature
}

\author{
Heather Cox $M D^{1}$, Michael Ma MD², Ronald Bridges $M D^{2}$, Estifanos Debru MD ${ }^{1}$, Oliver Bathe $M D^{1}$, \\ Francis Sutherland $M D^{1}$, Elijah Dixon MD $^{1}$
}

\begin{abstract}
H Cox, M Ma, R Bridges, et al. Well-differentiated intrahepatic cholangiocarcinoma in the setting of biliary papillomatosis: A case report and review of the literature. Can J Gastroenterol 2005;19(12):731-733.
\end{abstract}

A 64-year-old man presented with long-standing, vague, epigastric abdominal pain. History, physical examination and laboratory studies were noncontributory. However, serial computed tomography scans revealed a rapidly progressive mass in segment 2 of the liver. Surprisingly, surgical pathology revealed a well-differentiated intrahepatic cholangiocarcinoma associated with biliary papillomatosis (BP). BP is a rare, benign and potentially fatal disease of the intraand extrahepatic bile ducts. It is typified by numerous multicentric papillary fronds arising from biliary columnar epithelium. Most patients present with symptoms of jaundice and cholangitis. Although a benign disease, a review of the literature demonstrated that BP often recurs after surgical resection, carries a poor prognosis and has a moderately high malignant transformation rate. Treatment options for BP include surgical resection, transplant, ablation, stenting and/or bypass.

Key Words: Biliary papillomatosis; Cholangiocarcinoma; Mucinous neoplasms

\section{CASE PRESENTATION}

A 64-year-old man was investigated for long-standing, vague, epigastric abdominal pain. His pain had a recurring and relapsing time course. He had a history of peptic ulcer disease, hypertension and insulin-dependent diabetes, and he had undergone a laparoscopic cholecystectomy in the previous year. The patient had no history of jaundice, liver disease, hepatitis or alcohol abuse. His physical examination was normal. He was investigated with colonoscopy, chest x-ray, abdominal ultrasound, liver function tests and alpha-fetoprotein, all of which were normal. His hepatitis serology was negative. A computed tomography (CT) scan revealed a small, $2 \mathrm{~cm}$ heterogeneous focal mass in segment 2 of the liver. After consultation with the patient, expectant management of the liver lesion was undertaken. Follow-up ultrasound and a triphasic CT scan six months later revealed a progression; the hypovascular, hypoechoic liver mass had increased to $5.6 \mathrm{~cm}$ in greatest diameter. The mass was found overlying the umbilical fissure between segments 2, 3 and 4 (Figure 1). Centrally, part of the

\section{Un cholangiocarcinome intrahépatique bien différencié en présence d'une papillomatose biliaire : Rapport de cas et analyse bibliographique}

\begin{abstract}
Un homme de 64 ans a consulté en raison de douleurs abdominales épigastriques vagues de longue date. L'anamnèse, l'examen physique et les études de laboratoire n'ont pas été utiles. Cependant, la tomodensitométrie sérielle a révélé une masse à évolution rapide dans le segment 2 du foie. Curieusement, la pathologie chirurgicale a démontré la présence d'un cholangiocarcinome intrahépatique bien différencié associé à une papillomatose biliaire (PB). La PB est une maladie rare, bénigne et au potentiel fatal du canal cholédoque intrahépatique et extrahépatique. Elle se caractérise par de nombreuses frondes papillaires multicentriques provenant de l'épithélium prismatique biliaire. La plupart des patients manifestent des symptômes de jaunisse et de cholangite. Bien qu'il s'agisse d'une maladie bénigne, une analyse bibliographique a démontré que la PB refait souvent surface après une résection chirurgicale et s'associe à un mauvais pronostic et à un taux de transformation maligne modérément élevé. Les possibilités de traitement de la $\mathrm{PB}$ sont la résection chirurgicale, la greffe, l'ablation, la pose d'une endoprothèse ou un pontage.
\end{abstract}

lesion was vascular, and the periphery was hypovascular. There was mild distal bile duct dilation in segments 2 and 3. Given the interval change in size and concern that this represented a malignancy, surgical resection was recommended.

At laparotomy, the tumour was soft and fleshy, making it difficult to palpate the margins of the lesions. Intraoperative ultrasound was therefore important for defining the extent of resection. The patient underwent an uncomplicated left hepatectomy (segments 2, 3 and 4) and made an uneventful recovery.

Pathology revealed a well-differentiated intrahepatic cholangiocarcinoma associated with biliary papillomatosis (BP) (Figure 2). The resection margins were positive for BP. To assess whether there was papillomatosis in the remaining intrahepatic or extrahepatic bile ducts, postoperative endoscopic retrograde cholangiopancreatography (ERCP) and magnetic resonance cholangiopancreatography were performed. Neither showed evidence of a diffuse process. At the six-month follow-up, the patient was doing well, with no evidence of recurrence and complete resolution of his abdominal pain.

\footnotetext{
${ }^{1}$ Department of Surgery; ${ }^{2}$ Division of Gastroenterology, Department of Medicine, University of Calgary, Calgary, Alberta

Correspondence: Dr Elijah Dixon, Divisions of General Surgery and Surgical Oncology, Tom Baker Cancer Centre, 1331 - 29th Street Northwest,

Calgary, Alberta T2N 4N2. Telephone 403-944-8323, fax 403-283-1651, e-mail Elijah.Dixon@CalgaryHealthRegion.ca
}

Received for publication June 19, 2005. Accepted June 29, 2005 


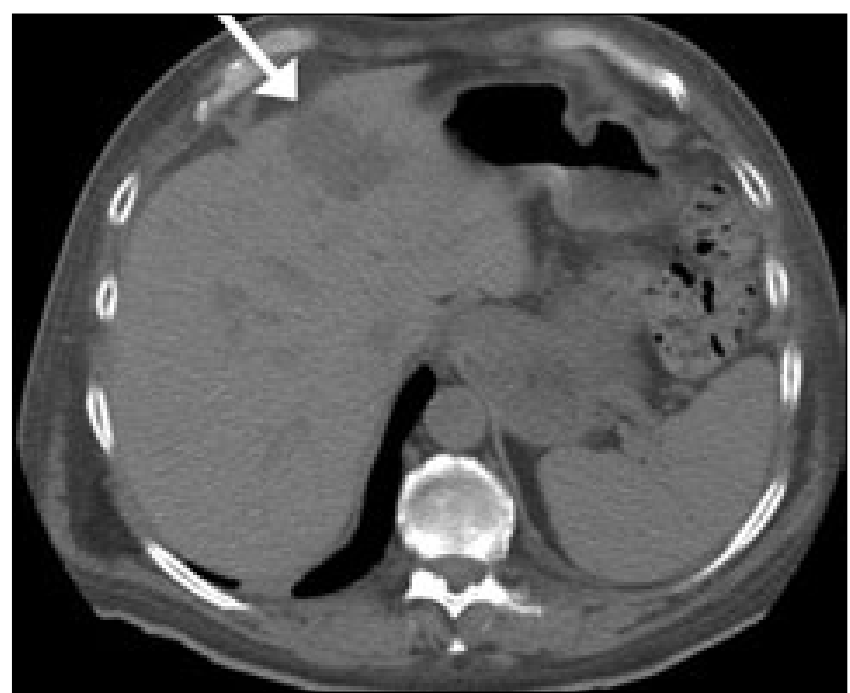

Figure 1) Unenhanced computed tomography scan showing a mass in segments 2, 3 and 4 of the liver (arrow)

\section{DISCUSSION}

BP is rare neoplasm first described by Caroli in 1959 (1). To date, there are fewer than 100 cases reported in the English literature $(2-5)$. BP has a 2:1 male to female ratio, and mean age at presentation is the seventh decade of life (60 to 70 years of age) (6). Initially, BP was thought to be a benign neoplasm associated with low malignant potential and an overproduction of mucin (7). However, recent studies are challenging this paradigm, noting that not all patients with BP have hypersecretion of mucin (6). In addition, malignant transformation rates are actually high, varying between $41 \%$ and $83 \%(3,4,6)$. Many patients with these benign premalignant papillary lesions of the biliary tract die from their disease (8).

Patients typically present with symptoms of abdominal pain, jaundice, acute cholangitis or weight loss. In the review by Lee et al (3), BP subtypes were characterized based on mucin hypersecretion. Patients with mucin-secreting BP were more likely to present with cholangitis, and have marked dilation of the intra- and extrahepatic ducts, whereas the $40 \%$ without hypersecretion of mucin were asymptomatic. Preoperative imaging may include ultrasound, CT, ERCP, magnetic resonance cholangiopancreatography and/or cholangioscopy. Classic image features include dilation of the intrahepatic and extrahepatic bile ducts secondary to mucinous secretions $(3,4)$. Extrusion of mucous from the ampulla of Vater may be seen during ERCP, similar to that seen in main duct intraductal papillary mucinous neoplasms (7).

Characterizing papillomatosis are many foci of multicentric papillary fronds of the intra- and extrahepatic biliary columnar epithelium $(2,6,7)$. The intrahepatic and/or extrahepatic biliary tree, including the gallbladder, can be variably involved (7). The papillary growth may be diffuse or confined to one segment. The distribution is approximately $40 \%$ to $45 \%$ intraand extrahepatic biliary tree, $25 \%$ intrahepatic only, $25 \%$ extrahepatic only, and the remaining involving only the gallbladder (6). Histologically, papilloma or villous tumours show fibrovascular stalks with branching papillary fronds, lined by columnar-to-cuboidal epithelial cells with basal nuclei (7). In one series, the papillary tumours were lined with cellular atypia and intracytoplasmic mucin secretion (4). Recently, a collection of fine needle aspiration features have been described to help

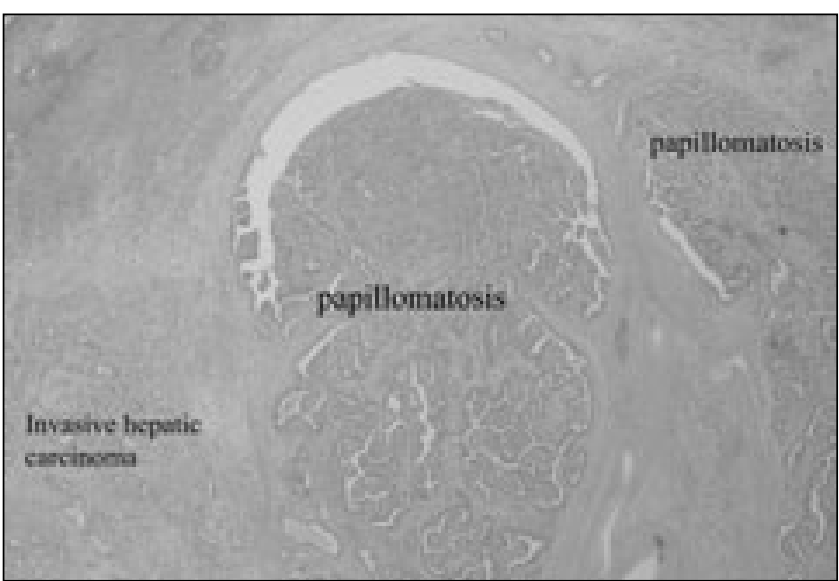

Figure 2) A representative histological slide demonstrating features of ductal papilloma adjacent to a well-differentiated cholangiocarcinoma

distinguish BP from cholangiocarcinoma. These included a hypercellular smear with double-cell layered sheets of ductal columnar epithelium, papillary configuration, preserved honeycomb pattern with equal nuclear spacing and dysplasia (9).

The pathogenesis of the disease is not yet known, but has been thought to be related to chronic biliary ductal inflammation from pancreatic juice reflux, biliary infection or stone disease (3). The resulting inflammation and duct dilation induces overproliferation of the bile duct epithelium followed by the dysplasia-carcinoma sequence $(3,4)$. The obstruction is thought to be due to mucous secretion or the enlarging papilloma (4).

Treatment for this benign disease has included surgery (including liver transplantation), palliative stenting, drainage or ablation (6,10-12). In general, if the disease is localized, lobectomy offers the best chance for cure $(6,8)$. Small, localized tumour masses may be ablated using radiofrequency when resection is not possible. Choledochotomy, tumour curettage and T-tube drainage have been used for tumours involving the common bile duct, which often prove to be the most challenging surgically (8). With diffuse and bilateral disease, liver transplantation may offer the only chance of cure $(8,10)$. Given that this is a new therapeutic option for BP, long-term follow-up data are not available. In cases where resection or transplantation is not possible, palliative stenting or bilioenteric drainage with a Hutson access loop may be valuable for preventing recurrent cholangitis (13).

$\mathrm{BP}$ is associated with high recurrence rates and poor prognosis secondary to septic complications $(8,14)$. Survival rates in the published case series are poorly reported, with incomplete follow-up. Without resection, the prognosis is poor, with median survival of 11 months $(6,15)$. Lee et al (3) found that 20 of 24 patients $(83 \%)$ with BP who underwent curative resection were alive after five years. Also, in a review of 76 patients, Yeung et al (6) found that the pooled mean survival time after resection for both malignant and benign $\mathrm{BP}$ was 28 months. The shorter survival time is likely due to the inclusion of malignant disease. In the same study, patients undergoing percutaneous drainage or laser ablation had survival rates ranging from six to 17 months.

Although BP is a rare condition, it is not without consequence. A high index of suspicion is required to diagnose BP, because it is prone to recurrence, has a high malignant potential and may be a diffuse process. The natural history of this 
benign disease usually commits patients to an intermittent course of recurrent abdominal pain, cholangitis and sepsis. Death is most often due to sepsis and/or liver failure. Given these potential complications, treatment recommendations involve resection, ablation, transplantation or palliative stenting and drainage. Furthermore, clinicians must be cognizant of the high likelihood of malignant transformation to cholangiocarcinoma.

\section{REFERENCES}

1. Caroli J. Papillomas and papillomatoses of the common bile duct. Rev Med Chir Mal Foie 1959;34:191-230.

2. Guglielmi A, Caputi Jambrenghi O, Verzillo F, et al. Biliary tract papillomatosis. Minerva Chir 2001;56:531-3.

3. Lee SS, Kim MH, Lee SK, et al. Clinicopathologic review of 58 patients with biliary papillomatosis. Cancer 2004;100:783-93.

4. Ma KF, Iu PP, Chau LF, Chong AK, Lam HS. Clinical and radiological features of biliary papillomatosis. Australas Radiol 2000;44:169-73.

5. Seo DW, Lee SK, Kim MH. Biliary papillomatosis. Gastrointest Endosc 2000;51:67.

6. Yeung YP, AhChong K, Chung CK, Chun AY. Biliary papillomatosis: Report of seven cases and review of English literature. J Hepatobiliary Pancreat Surg 2003;10:390-5.
7. Shimonishi T, Sasaki M, Nakanuma Y. Precancerous lesions of intrahepatic cholangiocarcinoma. J Hepatobiliary Pancreat Surg 2000; 7:542-50.

8. Helling TS, Strobach RS. The surgical challenge of papillary neoplasia of the biliary tract. Liver Transpl Surg 1996;2:290-8.

9. Tsui WM, Lam PW, Mak CK, Pay KH. Fine-needle aspiration cytologic diagnosis of intrahepatic biliary papillomatosis (intraductal papillary tumor): Report of three cases and comparative study with cholangiocarcinoma. Diagn Cytopathol 2000;22:293-8.

10. Beavers KL, Fried MW, Johnson MW, et al. Orthotopic liver transplantation for biliary papillomatosis. Liver Transpl 2001;7:264-6.

11. Dumortier J, Scoazec JY, Valette PJ, Ponchon T, Boillot O. Successful liver transplantation for diffuse biliary papillomatosis. J Hepatol 2001;35:542-3.

12. Lam CM, Yuen ST, Yuen WK, Fan ST. Biliary papillomatosis. Br J Surg 1996;83:1715-6.

13. Bathe OF, Pacheco JT, Ossi PB, et al. A subcutaneous or subfascial jejunostomy is beneficial in the surgical management of extrahepatic bile duct cancers. Surgery 2000;127:506-11.

14. Albores-Saavedra J, Murakata L, Krueger JE, Henson DE. Noninvasive and minimally invasive papillary carcinomas of the extrahepatic bile ducts. Cancer 2000;89:508-15.

15. Okamoto A, Tsuruta K, Matsumoto G, et al. Papillary carcinoma of the extrahepatic bile duct: Characteristic features and implications in surgical treatment. J Am Coll Surg 2003;196:394-401. 


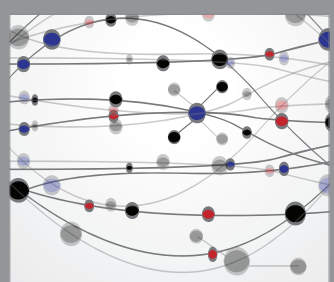

The Scientific World Journal
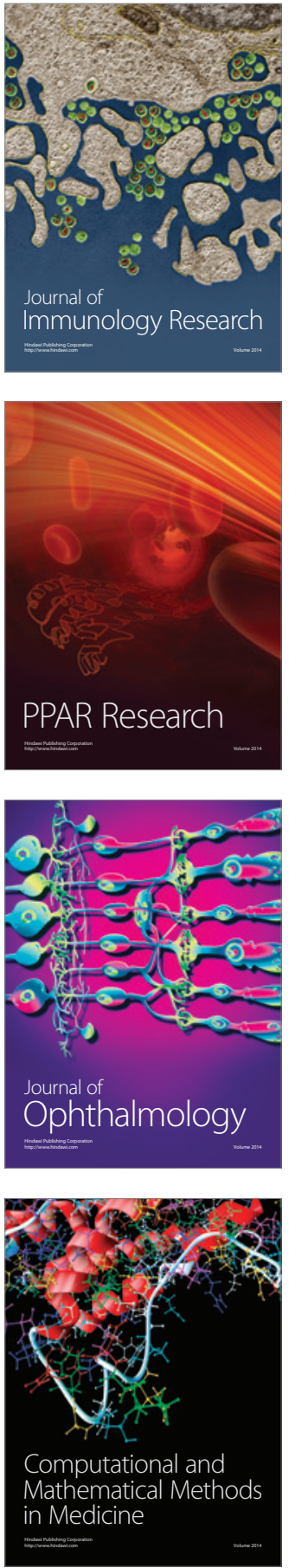

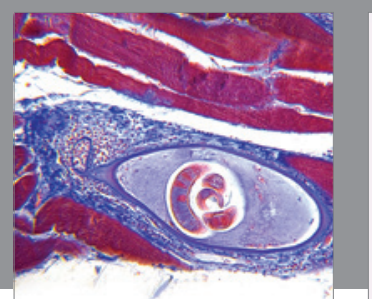

Gastroenterology Research and Practice

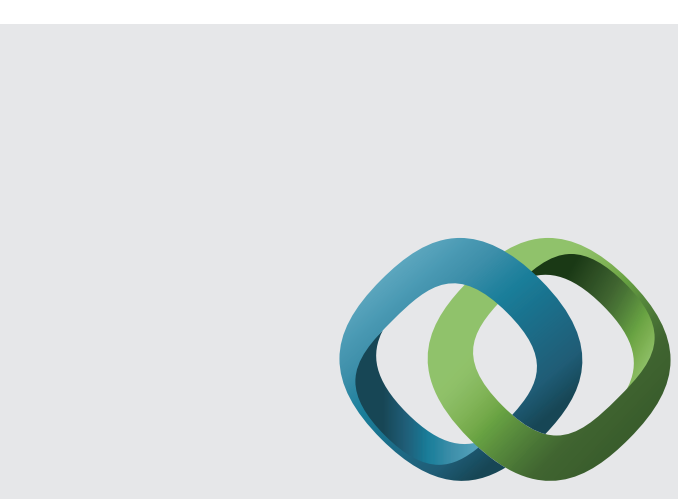

\section{Hindawi}

Submit your manuscripts at

http://www.hindawi.com
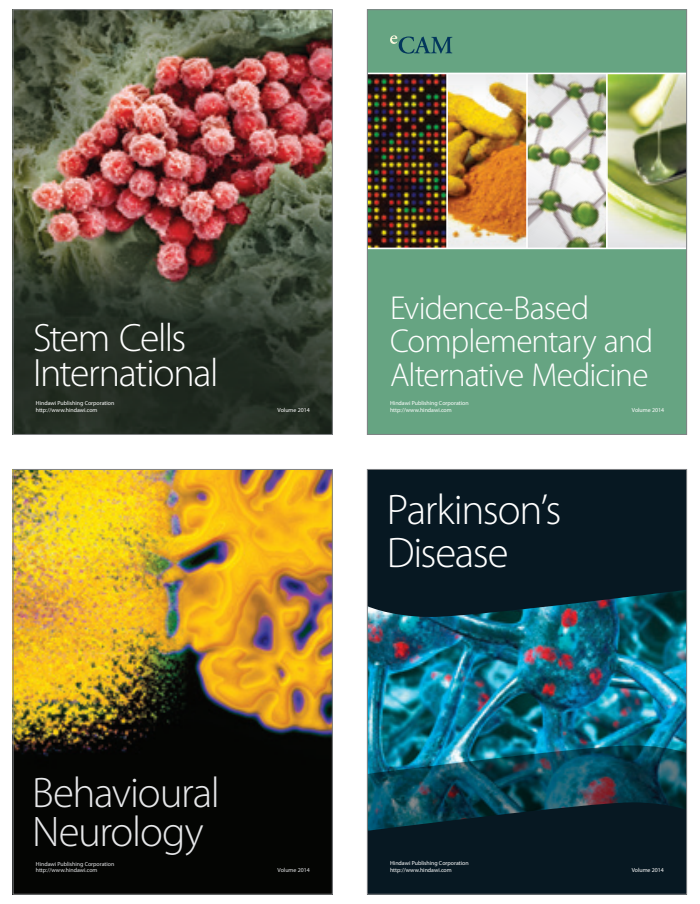
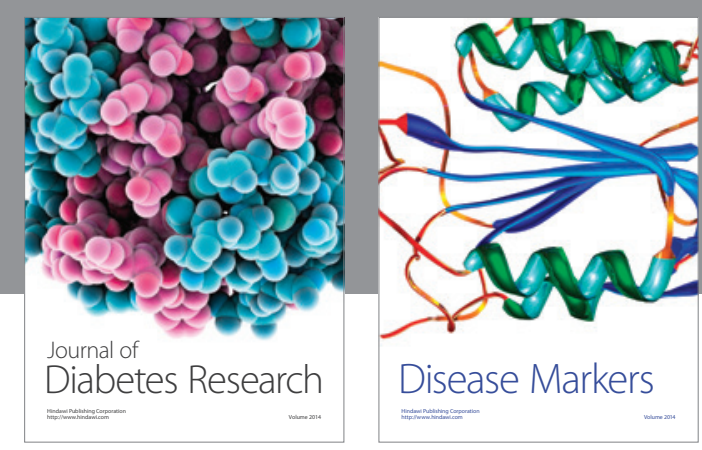

Disease Markers
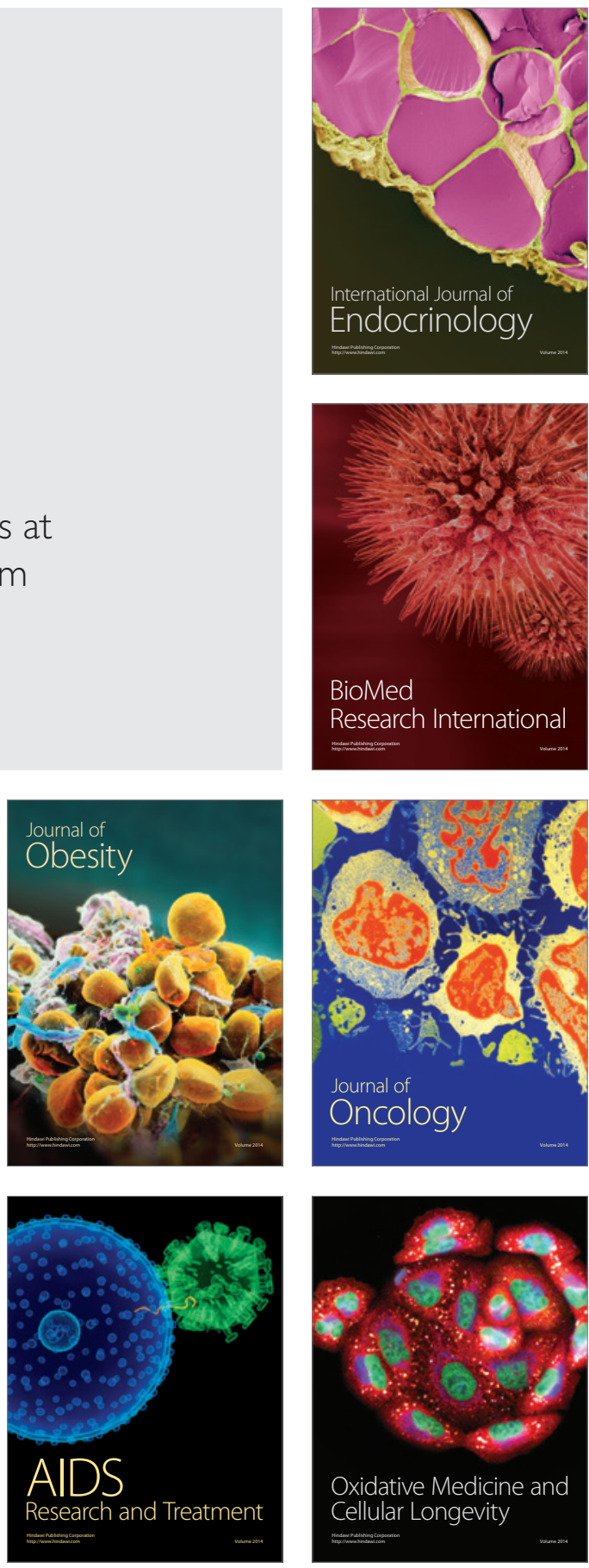